\title{
Consumo e Absorção Aparente de Macroelementos Minerais, em Bezerros Alimentados com Dietas Contendo Diferentes Níveis de Volumoso ${ }^{1}$
}

\author{
Gherman Garcia Leal de Araújo², José Fernando Coelho da Silva ${ }^{3}$, Sebastião de Campos \\ Valadares Filho ${ }^{3}$, Oriel Fajardo de Campos $^{4}$, Ricardo Dias Signoretti ${ }^{5}$, Silvia Helena Nogueira Turco ${ }^{5}$
}

RESUMO - Avaliaram-se os efeitos de diferentes níveis de volumoso nas dietas sobre o consumo e a absorção aparente (AP) de cálcio $(\mathrm{Ca})$, fósforo $(\mathrm{P})$, magnésio $(\mathrm{Mg})$, sódio $(\mathrm{Na})$ e potássio $(\mathrm{K})$. Utilizaram-se 40 bezerros, com peso vivo médio inicial de $60 \mathrm{~kg}$, distribuídos em delineamento inteiramente casualizado e alimentados à vontade com rações na base da MS, com níveis crescentes de 10 , 25, 40, 55 e 90\% de feno de capim-coastcross (Cynodon dactylon) picado. Os coeficientes de absorção aparente foram obtidos por intermédio de ensaios de digestibilidade, realizados aos 120 e 180 dias de idade dos animais, sendo usado como indicador o óxido crômico para estimar a excreção fecal. Os consumos de $\mathrm{Ca}, \mathrm{P}, \mathrm{Mg}, \mathrm{Na}$ e $\mathrm{K}$, expressos em g/dia, sofreram efeito quadrático, estimando-se os respectivos consumos máximos com os níveis de 47,0; 30,0; 45,3; 41,0; e 51,8\% de volumoso na dieta. As absorções aparentes do Ca, $\mathrm{P}$ e $\mathrm{K}$ foram afetadas pelos níveis de volumoso nas dietas, que apresentaram comportamento quadrático e máximas absorções de 58,7; 56,1 ; e $78,3 \%$ para os níveis de 20,3;23,1; e 45,2\% de volumoso nas dietas, respectivamente.

Palavras-chave: absorção aparente, bezerros, cálcio, consumo, fósforo, magnésio, potássio, sódio, volumoso

\section{Intake and Apparent Absorption of Calcium, Phosphorus, Sodium, Potassium and Magnesium of Calves Fed Diets with Different Levels of Roughage}

\begin{abstract}
The effects of different levels of roughage on intake and apparent absorption of calcium (Ca), phosphorus (P), sodium $(\mathrm{Na})$, potassium $(\mathrm{K})$ and magnesium $(\mathrm{Mg})$ were studied. Forty Holstein x Zebu calves, with initial average live weight of $60 \mathrm{~kg}$, allotted to a completely randomized design, were fed concentrate and chopped coastcross (Cynodon dactylon) grass hay ad libitum in the following levels: $10 ; 25 ; 40 ; 55$ e 90\%, on a DM basis. The coefficients of apparent absorption were obtained by one experiment with two experimental periods of digestibility, accomplished at 120 and 180 days of age of the animals. The fecal dry matter excretion was estimated with chromium oxide. The intakes of $\mathrm{Ca}, \mathrm{P}, \mathrm{Mg}, \mathrm{Na}$ and $\mathrm{K}$ in ( $\mathrm{g}$ /day) showed a quadratic effect and the respective maximum intakes were estimated for 47.0, 30.0, 45.3, 41.0 and $51.8 \%$ of roughage in the diet. The apparent absorption coefficients of Ca, P and K were affected by the level of roughage, showing a quadratic effect, with the respective maximum absorptions of $58.7,56.1$ and $78.3 \%$ for the levels of $20.3,23.1$ and $45.2 \%$ of hay in the diet.
\end{abstract}

Key Words: apparent absorption, calves, calcium, feed intake, magnesium, phosphorus, potassium, roughage, sodium

\section{Introdução}

A quantidade de cálcio absorvido no aparelho digestivo depende, além da disponibilidade do elemento no alimento, da exigência e da quantidade ingerida. Para atender às exigências, a dieta deve conter cálcio em quantidade suficiente e disponível para a absorção. Em muitos dos resultados publicados sobre ensaios de balanço de cálcio, as quantidades ingeridas são freqüentemente maiores que as exigidas. Nesta situação, os coeficientes de absorção observados e esperados tendem a ser os mesmos e iguais a R/I, em que R e I são, respectivamente, a exigência e a ingestão de cálcio. Se o cálcio dietético não estiver em uma forma completamente disponível, o coeficiente de absorção observado será mais baixo que o esperado, nos ensaios de balanço em que as ingestões e as exigências são da mesma ordem (COELHO DA SILVA, 1995).

Diferentes valores de absorção aparente têm sido encontrados para cálcio, sob diversas dietas, como: 16,3\% (CARVALHO, 1996), 23,4\% (COELHO da SILVA et al., 1991), 32,8\% (RABELLO et al., 1994), 33 a 68\% (FIELD, 1983), 36,2 (ARAÚJO et al.,

\footnotetext{
1 Trabalho realizado pelo convênio UFV-DZO/Embrapa Gado de Leite, parte da tese de D.Sc. do $1^{\circ}$ autor.

2 Pesquisador Embrapa Semi-Árido, Bolsista do CNPq, BR 428, Km 152, CP 23, Petrolina-PE, CEP 56300-000. E.mail: ggla@cpatsa.embrapa.br

3 Professores Titulares DZO-UFV, Pesquisadores CNPq.

4 Pesquisador Embrapa Gado de Leite.

${ }^{4}$ Eng. Agrônomo, Doutor em Zootecnia.

5 Professora Adjunta, DTCS-UNEB.
} 
1994), 38,0\% (NATIONAL RESEARCH COUNCIL NRC, 1988), 47,9\% (VALADARES FILHO et al., 1991b), 68,0\% (AGRICULTURAL RESEARCH COUNCIL - ARC, 1980), 78,2\% (ROSADO, 1991) e 15,0 a 68,0\% (COELHO da SILVA, 1995). Todavia, o NRC (1988) cita o valor de $38 \%$ para a absorção verdadeira de $\mathrm{Ca}$.

A absorção do fósforo depende de vários fatores, como fonte de fósforo, presença de cálcio nos diferentes tecidos, variação entre animais, entre outros. Alguns valores de coeficientes de absorção aparente de $\mathrm{P}$, disponíveis na literatura, variam de 30,5 a $58,0 \%$. De acordo com alguns autores, as absorções aparentes foram de 30,5\% (CARVALHO, 1996), 44,3\% (VALADARES FILHO et al., 1991b), 43,6\% (ARAÚJO, et al., 1994), 45,0 e 46,2\% (ROSADO, 1991) e 57,7\% (COELHO da SILVA et al., 1991). Absorções verdadeiras de 50 e $58 \%$ são citadas, respectivamente, pelo NRC (1988) e ARC (1980).

Os coeficientes de absorção do magnésio são extremamente variáveis, podendo também haver grande variação entre indivíduos. Alguns resultados médios obtidos para a absorção aparente de $\mathrm{Mg}$ mostram ampla variação em diferentes dietas, sendo 16,3\% (COELHO da SILVA et al., 1991), 18,4\% (GREENE et al., 1988), 23,7\% (CARVALHO, 1996), 36,6\% (RABELLO et al., 1994), 43,7\% (ROSADO, 1991), 51,5\% (ARAÚJO etal., 1994) e 56,9\% (VALADARES FILHO et al., 1991a). O ARC (1980) adotou o valor de $20 \%$ para absorção verdadeira de $\mathrm{Mg}$.

A absorção aparente de $\mathrm{Na}$, verificada por vários autores, foi de 49,8 e 63,2\% (ROSADO, 1991), 59,2\% (VALADARES FILHO et al., 1991a), 75\% (COELHO da SILVA et al., 1991), 80,5\% (RABELLO et al., 1994) e 89,1\% (CARVALHO, 1996); porém, para a absorção verdadeira, o valor adotado pelo ARC (1980) é de 91,0\%. A absorção aparente de K variou de 29,5 a 51,9\% (ROSADO, 1991), 67,9\% (VALADARES FILHO et al., 1991a), 70,3\% (CARVALHO, 1996), 80,8\% (ARAÚJO et al., 1994) e 85,0\% (RABELLO et al., 1994). O NRC (1988) citou que a absorção verdadeira de K varia de 91 a $100 \%$.

BEN-GHEDALIA et al. (1996) observaram, em vacas lactantes, absorções aparentes de $\mathrm{Ca}, \mathrm{P}, \mathrm{Mg}$, $\mathrm{Na}$ e K, variando de 22,3 a 30,$1 ; 39,1$ a 45,$3 ; 29,4$ a 45,$6 ; 84,2$ a 70,2; e 79,4 a 86,7\%, respectivamente.

São poucas as informações encontradas na literatura, em relação aos níveis de volumoso e concentrado nas dietas de bezerros, bem como essa relação influi na cinética da digestão e na utilização dos minerais existentes nos alimentos.

O presente trabalho foi conduzido visando avaliar efeito de diferentes níveis de volumosos sobre os consumos e as absorções aparentes de $\mathrm{Ca}, \mathrm{P}, \mathrm{Na}, \mathrm{K}$ e $\mathrm{Mg}$, utilizando-se 40 bezerros mestiços Holandês $\times$ Zebu em crescimento.

\section{Material e Métodos}

O local e o período de realização do experimento, os animais, o manejo alimentar e as amostragens foram descritas por ARAÚJO et al. (1998).

Nos estudos de consumo e absorção aparente de cálcio $(\mathrm{Ca})$, fósforo $(\mathrm{P})$, magnésio $(\mathrm{Mg})$, potássio $(\mathrm{K})$ e sódio $(\mathrm{Na})$, foram formuladas dietas com base nas exigências nutricionais, segundo as normas do NRC (1989), para ganho esperado de $1,0 \mathrm{~kg} /$ dia.

Os animais foram alimentados à vontade com rações na base da MS, com níveis crescentes de 10 , $25,40,55$ e $90 \%$ de feno de capim-coastcross (Cynodon dactylon) picado. Os coeficientes de absorção aparente foram obtidos por intermédio de ensaios de digestibilidade, realizados aos 120 e 180 dias de idade dos animais, que constaram de dez dias de adaptação e seis dias de coletas. Para a determinação do fluxo de matéria seca fecal, foi utilizado o óxido crômico em pó $\left(\mathrm{Cr}_{2} \mathrm{O}_{3}\right)$ como indicador externo, duas vezes ao dia, sendo $2,5 \mathrm{~g}$ pela manhã e $2,5 \mathrm{~g}$ à tarde, via oral, durante dez dias do período de adaptação e seis dias do período de coleta de amostras. Os consumos citados referem-se apenas aos períodos de digestibilidade. A composição química das dietas na base da MS encontra-se na Tabela 1.

As concentrações de cromo nas amostras fecais foram determinadas segundo Willians e colaboradores (1962), citados por SILVA (1990), e os cálculos dos fluxos de matéria seca realizados conforme COELHO DA SILVA e LEÃO (1979).

Os teores de cálcio $(\mathrm{Ca})$, fósforo $(\mathrm{P})$, magnésio $(\mathrm{Mg})$, potássio $(\mathrm{K})$ e sódio $(\mathrm{Na})$ foram determinados na solução mineral, obtida pela digestão via-úmida. $\mathrm{O}$ $\mathrm{Ca}$ e o $\mathrm{Mg}$ foram determinados por espectrofotometria de absorção atômica; o $\mathrm{P}$, por colorimetria; e o Na e o K, por espectrofotometria de chama, conforme técnicas descritas por SILVA (1990).

Utilizou-se delineamento experimental inteiramente casualizado, com cinco tratamentos e oito repetições. As análises estatísticas das variáveis estudadas foram interpretadas por análises de variância e regressão, 
Tabela 1 - Teores de matéria seca (MS), proteína bruta (PB), fibra em detergente neutro (FDN), cálcio ( $\mathrm{Ca})$, fósforo $(\mathrm{P})$, magnésio $(\mathrm{Mg})$, sódio $(\mathrm{Na})$ e potássio (K) das dietas contendo diferentes níveis de volumoso

Table 1 - Contents of dry matter (DM), crude protein (CP), neutral detergent fiber (NDF), calcium (Ca), phosphorus $(P)$, magnesium $(\mathrm{Mg})$, sodium $(\mathrm{Na})$ and potassium $(\mathrm{K})$ of diets with different levels of roughage

Níveis de volumoso (\%)

\begin{tabular}{lrrrrr} 
& \multicolumn{5}{c}{$\begin{array}{c}\text { Níveis de volumoso (\%) } \\
\text { Roughage levels (\%) }\end{array}$} \\
\cline { 2 - 6 } Itens & \multicolumn{1}{c}{10} & \multicolumn{1}{c}{25} & \multicolumn{1}{c}{40} & \multicolumn{1}{c}{55} & \multicolumn{1}{c}{90} \\
\hline $\mathrm{MS}, \%$ & 88,26 & 88,66 & 88,22 & 88,42 & 88,60 \\
$\mathrm{DM}$ & & & & & \\
$\mathrm{PB}^{1}$ & 15,64 & 15,56 & 15,84 & 15,13 & 8,00 \\
$\mathrm{FDN}^{1}$ & 18,88 & 27,40 & 38,18 & 48,03 & 71,36 \\
$\mathrm{Ca}^{1}$ & 1,31 & 1,22 & 1,28 & 1,25 & 0,52 \\
$\mathrm{P}^{1}$ & 0,35 & 0,32 & 0,33 & 0,34 & 0,26 \\
$\mathrm{Mg}^{1}$ & 0,10 & 0,10 & 0,12 & 0,12 & 0,13 \\
$\mathrm{Na}^{1}$ & 0,60 & 0,54 & 0,66 & 0,68 & 0,55 \\
$\mathrm{~K}^{1}$ & 0,86 & 0,98 & 1,15 & 1,26 & 1,08 \\
\hline
\end{tabular}

${ }^{1}$ Porcentagem na MS (Percentage in DM).

utilizando-se o sistema de análises estatísticas e genéticas SAEG (UNIVERSIDADE FEDERAL DE VIÇOSA - UFV, 1995), enquanto os coeficientes de regressão foram comparados pelo teste de " $\mathrm{t}$ ", adotando-se os níveis de 1 e $5 \%$ de probabilidade.

\section{Resultados e Discussão}

Os consumos de $\mathrm{Ca}, \mathrm{P}, \mathrm{Mg}, \mathrm{Na}$ e $\mathrm{K}$, expressos em g/dia, e suas respectivas equações de regressão são apresentados na Tabela 2. Observou-se comportamento quadrático para os consumos de todos macroelementos, estimando-se os consumos máximos para os níveis de 47,$0 ; 30,0 ; 45,3 ; 41,0$; e $51,8 \%$ de volumoso na dieta, respectivamente. CARVALHO (1996), que também observou comportamento quadrático para os consumos de $\mathrm{P}$ e $\mathrm{Na}$, verificou que o consumo máximo de $\mathrm{P}$ foi obtido com o nível de $43,0 \%$ e o mínimo de $\mathrm{Na}$, com $20,9 \%$ de concentrado nas rações.

Trabalhando com bezerros da raça Holandesa, SIGNORETTI et al. (1999) utilizaram dietas com quatro níveis de feno de coastcross $(10,25,40$ e $55 \%$ ) e observaram que o consumo de $\mathrm{Ca}$ não foi influenciado pelos níveis de volumoso, diferentemente do ocorrido no presente trabalho. Entretanto, o consumo de $\mathrm{P}$ teve comportamento quadrático, estimando-se consumo máximo de $10,9 \mathrm{~g} /$ dia para o nível de $42,4 \%$ de volumoso na dieta. Os consumos de $\mathrm{Mg}$ e $\mathrm{K}$ aumentaram, enquanto o de $\mathrm{Na}$ decresceu linearmente com adição de volumoso nas dietas.
FERREIRA et al. (1999) usaram bovinos mestiços $\mathrm{F}_{1}$ Simental $\mathrm{x}$ Nelore com peso vivo médio inicial de $354 \mathrm{~kg}$ e idade média de 17 meses. Os animais receberam dietas contendo níveis crescentes de concentrado de 25,0;37,5; 50,0;62,5; e 75,0\%. Esses autores observaram comportamento quadrático $(\mathrm{P}<0,01)$ para o consumo do $\mathrm{Ca}$ e ajuste de forma linear $(\mathrm{P}<0,01)$ para os consumos de fósforo $(\mathrm{P})$, magnésio $(\mathrm{Mg})$ e potássio $(\mathrm{K})$, tendo o consumo de $\mathrm{P}$ aumentado e os de $\mathrm{Mg}$ e $\mathrm{K}$ decrescido, com o aumento na proporção de concentrados nas rações. Segundo os autores, este fato pode ser explicado, em parte, pelo aumento da concentração de $\mathrm{P}$ e pela diminuição dos teores de $\mathrm{Mg}$ e $\mathrm{K}$ das rações. Entretanto, não foi verificado efeito dos níveis de concentrados no consumo de sódio.

Embora tenham ocorrido diferenças entre os tratamentos para os consumos de $\mathrm{Ca}, \mathrm{P}, \mathrm{Mg}, \mathrm{Na}$ e $\mathrm{K}$, os valores médios calculados a partir da Tabela 2 , excetuando-se o tratamento com $90 \%$ de volumoso, foram de 56,6 ; 14,$2 ; 4,7 ; 29,6 ;$ e 41,1 g/dia, respectivamente, permitem relatar que os mesmos estão próximos dos recomendados pelo NRC (1988), para os animais utilizados.

Os coeficientes de absorções aparentes de $\mathrm{Ca}$, $\mathrm{P}, \mathrm{Mg}, \mathrm{Na}$ e $\mathrm{K}$, com suas respectivas equações de regressão, são mostrados na Tabela 3. Os coeficientes de absorção aparente de $\mathrm{Ca}, \mathrm{P}$ e $\mathrm{K}$ apresentaram comportamento quadrático, em função dos níveis de volumoso nas dietas, estimando-se máximas absorções de 58,$7 ; 56,1$; e 78,3\% para os níveis de 20,$3 ; 23,1$; e $45,2 \%$ de volumoso nas dietas, respectivamente.

Observaram-se absorções aparentes de Ca variando de 29,1 a $68,8 \%$, cuja média foi de 52,6\%. Estes resultados foram próximos aos encontrados por RABELLO et al. (1994), FIELD (1983), ARAÚJO et al. (1994), NRC (1988) e VALADARES FILHO et al. (1991b), de 32,8; 33;0 a 68,0;36,2; 38,8; e $47,9 \%$, respectivamente. O ARC (1980) menciona absorção real de $68,0 \%$ para o cálcio.

As absorções aparentes de $\mathrm{P}$ variaram de 31,3 a 63,2, com média de 51,9\%. ROSADO (1991) e COELHO DA SILVA (1995) observaram valores de absorção de 46,2 e 57,7\%, respectivamente. As médias dos autores citados estão dentro da variação encontrada no presente trabalho. O ARC (1980) cita absorção verdadeira de fósforo de $50,0 \%$ e o NRC (1988), de 58,0\%.

Obtiveram-se absorções aparentes de $\mathrm{K}$ variando de 78,2 a $86,3 \%$, sendo bastante similares às encon- 
Tabela 2 - Médias, coeficientes de variação (CV) e equações de regressão ajustadas (ER), para os consumos de cálcio (Ca), fósforo $(\mathrm{P})$, magnésio $(\mathrm{Mg})$, sódio $(\mathrm{Na})$ e potássio $(\mathrm{K})$, expressos em gramas por dia (g/dia), em função dos níveis de volumoso nas dietas

Table 2 - Means, coefficients of variation (CV) and fitted regression equations (RE) for calcium (Ca), phosphorus (P), magnesium (Mg), sodium (Na), and potassium (K) intakes, in grams per day, in function of the levels of roughage in diets

\begin{tabular}{|c|c|c|c|c|c|c|c|}
\hline \multirow[b]{2}{*}{ Itens } & \multicolumn{5}{|c|}{$\begin{array}{l}\text { Níveis de volumoso, \% } \\
\text { Roughage levels }\end{array}$} & \multirow[b]{2}{*}{$\mathrm{CV}(\%)$} & \multirow[b]{2}{*}{$\begin{array}{l}\mathrm{ER} \\
R E\end{array}$} \\
\hline & 10 & 25 & 40 & 55 & 90 & & \\
\hline $\mathrm{Ca}$ & 49,98 & 67,98 & 53,57 & 54,42 & 14,08 & 39,91 & 1 \\
\hline $\mathrm{P}$ & 13,60 & 16,44 & 13,66 & 13,19 & 6,54 & 34,56 & 2 \\
\hline $\mathrm{Mg}$ & 3,92 & 4,91 & 4,67 & 5,40 & 3,12 & 35,46 & 3 \\
\hline $\mathrm{Na}$ & 28,11 & 28,11 & 29,41 & 33,05 & 17,62 & 41,11 & 4 \\
\hline $\mathrm{K}$ & 31,55 & 38,84 & 42,63 & 51,44 & 32,15 & 35,24 & 5 \\
\hline \multicolumn{6}{|c|}{ 1. $\hat{\mathrm{Y}}=45,17+0,94 * \mathrm{~V}-0,01 * * \mathrm{~V}^{2}$} & \multicolumn{2}{|c|}{$\mathrm{R}^{2}=0,93$} \\
\hline \multicolumn{6}{|c|}{ 2. $\hat{\mathrm{Y}}=13,26+0,12 * \mathrm{~V}-0,002 * * \mathrm{~V}^{2}$} & \multicolumn{2}{|c|}{$\mathrm{R}^{2}=0,93$} \\
\hline \multicolumn{6}{|c|}{ 3. $\hat{\mathrm{Y}}=3,12+0,09 * \mathrm{~V}-0,0001 * * \mathrm{~V}^{2}$} & \multicolumn{2}{|c|}{$\mathrm{R}^{2}=0,89$} \\
\hline \multicolumn{6}{|c|}{ 4. $\hat{\mathrm{Y}}=23,04+0,41 * \mathrm{~V}-0,005 * * \mathrm{~V}^{2}$} & \multicolumn{2}{|c|}{$\mathrm{R}^{2}=0,86$} \\
\hline \multicolumn{6}{|c|}{ 5. $\hat{\mathrm{Y}}=20,76+1,03 * \mathrm{~V}-0,001 * * \mathrm{~V}^{2}$} & \multicolumn{2}{|c|}{$\mathrm{R}^{2}=0,87$} \\
\hline
\end{tabular}

* $\mathrm{e}^{* *}$ Significativo a 5 e $1 \%$ de probabilidade, respectivamente, pelo teste de "t".

* and ** Significant at 5 and $1 \%$ of probability, respectively, by " $t$ " test.

V. Nível de volumoso nas dietas (\%) Level of roughage in diets (\%).

Tabela 3 - Médias, equações de regressão ajustadas (ER) e coeficientes de determinação $\left(R^{2}\right)$ para as absorções aparente de cálcio $(\mathrm{Ca})$, fósforo $(\mathrm{P})$, magnésio $(\mathrm{Mg})$, sódio $(\mathrm{Na})$ e potássio $(\mathrm{K})$, em função dos níveis de volumoso nas dietas Table 3 - Means, coefficients of variation (CV) and fitted regression equations (RE) for calcium (Ca), phosphorus (P), magnesium (Mg), sodium (Na) and potassium (K) of the total apparent absorption, in grams per day, in function of the levels of roughage in diets

\begin{tabular}{lcccccr}
\hline \multicolumn{7}{c}{ Níveis de volumoso, $\%$} \\
Roughage levels
\end{tabular}

$1 . \hat{\mathrm{Y}}=58,61+0,28 \mathrm{~V}-0,0060 * \mathrm{~V}^{2}$

2. $\hat{\mathrm{Y}}=56,06+0,30 \mathrm{~V}-0,0065^{* *} \mathrm{~V}^{2}$

3. $\hat{\mathrm{Y}}=78,14+0,28 * * \mathrm{~V}-0,0031 * * \mathrm{~V}^{2}$

* $\mathrm{e}^{* *}$ Significativo a 5 e $1 \%$ de probabilidade, respectivamente, pelo teste de "t".

* and ** Significant at 5 and $1 \%$ of probability, respectively, by " $t$ " test.

V. Nível de volumoso nas dietas (\%) Level of roughage in diets (\%).

tradas por BEN-GHEDALIA et al. (1996), ARAÚJO et al. (1994) e RABELLO et al. (1994), respectivamente, 79,4 a 86,$7 ; 80,8$; e $85,0 \%$. O NRC (1988) cita que a absorção verdadeira de K varia de 91 a $100 \%$.

Os coeficientes de absorção aparente do $\mathrm{Mg}$ e $\mathrm{Na}$ não foram afetados pelos níveis de volumosos, apresentando valores médios de 45,1 e 93,6\%, respectivamente. $\mathrm{O}$ valor obtido para o $\mathrm{Mg}$ foi relativamente próximo aos encontrados por ROSADO (1991) e ARAÚJO et al. (1994), respectivamente, 43,7 e 51,5\%. A absorção aparente média do Na foi próxima à citada pelo ARC (1980), 91,0\%, para absorção verdadeira, e ao valor de absorção aparente de $89,1 \%$ obtido por CARVALHO (1996).

SIGNORETTI et al. (1999) observaram que os coeficientes de absorção aparente de $\mathrm{Ca}, \mathrm{P}, \mathrm{Mg}$ e Na não foram influenciados pelos diferentes níveis de feno nas dietas, mas a de $\mathrm{K}$ decresceu linearmente 
$(\mathrm{P}<0,05)$. A absorção aparente de $\mathrm{Ca}$ e $\mathrm{P}$ foi, em média, de 56,1 e 47,9\%, respectivamente. Ao se comparar com os valores encontrados no presente trabalho, para os mesmos minerais, observa-se que a absorção de Ca foi próxima e a de $\mathrm{P}$, inferior.

\section{Conclusões}

Os diferentes níveis de volumoso nas dietas influenciaram os consumos dos diferentes minerais avaliados, obtendo-se valores máximos de ingestão de $\mathrm{Ca}, \mathrm{P}, \mathrm{Mg}, \mathrm{Na}$ e K expressos em g/dia, com níveis de 47,$0 ; 30,0 ; 45,3 ; 41,0$; e $51,8 \%$ de volumoso nas dietas, respectivamente, para bezerros.

As médias obtidas dos coeficientes de absorção aparente dos minerais estudados estão próximas às encontradas nas literaturas citadas.

A absorção de cálcio, fósforo e potássio foi influenciada pelos níveis de feno nas dietas, estimando-se valores máximos de absorção de 58,7; 56,1; e $78,3 \%$, respectivamente, para $\mathrm{Ca}, \mathrm{P}$ e $\mathrm{K}$, com os níveis de 20,3;23,1; e 45,2\% de volumoso nas dietas, respectivamente, para bezerros.

\section{Referências Bibliográficas}

AGRICULTURAL RESEARCH COUNCIL - ARC. 1980. The nutrient requirements of ruminant livestock. London. 351p.

ARAÚJO, G.G.L., COELHO DA SILVA, J.F., VALADARES FILHO, S.C. et al. 1994. Absorções aparentes totais e parciais de cálcio, magnésio, fósforo e potássio pelas vacas lactantes. R. Bras. Zootec., 23(5):773-781.

ARAÚJO, G.G.L., COELHO DA SILVA, J.F., VALADARES FILHO, S.C. et al. 1998. Consumo e digestibilidade total dos nutrientes de dietas contendo diferentes níveis de volumoso, em bezerros. R. Bras. Zootec., 27(2):345-354.

BEN-GHEDALIA, D., MIRON, J., YOSEF, E. 1996 Appparent digestibility of minerals by lactating cows from a total mixed ration supplemented with poultry litter. J. Dairy Sci., 79:454-458.

CARVALHO, A.U. Niveis de concentrado na dieta de zebuinos: consumo, digestibilidade e eficiência microbiana Viçosa, MG: UFV, 1996. 112p. Tese (Doutorado em Zootecnia) Universidade Federal de Viçosa, 1996.

COELHO DA SILVA, J.F., LEÃO, M.I. 1979. Fundamentos de nutrição dos ruminantes. Piracicaba: Livroceres. 380p.

COELHO DA SILVA, J.F., VALADARES FILHO, S.C. LEÃO, M.I. et al. 1991 Efeito da monensina sódica e da uréia sobre o consumo, parâmetros ruminais, digestibilidade aparente e balanço nutricional em bovinos. R. Soc. Bras. Zootec., 20(5):454-470.

COELHODA SILVA, J.F. Exigências de macroelementos inorgânicos para bovinos: O sistema ARC/AFRC e a experiência no Brasil. In: SIMPÓSIO INTERNACIONAL SOBRE EXIGÊNCIAS NUTRICIONAIS DE RUMINANTES, 1, 1995, Viçosa, MG. Anais... Viçosa, MG: JARD, 1995. p.467-504.
FERREIRA, M.A., VALADARES FILHO, S.C., COELHO DA SILVA, J.F. et al. 1999 Consumo, conversão alimentar, ganho de peso e características da carcaça de bovinos $\mathrm{F}_{1}$ Simental $\mathrm{x}$ Nelore. R. Bras. Zootec. 28(2):343-351.

FIELD, A.C. 1983. A review of requeriments of dairy and beef cattle for major elements. Livest. Prod. Sci., 10(4):327-338.

GREENE, L.W., MAY, B.J., SCHELLING, G.T. et al. 1988. Site and extent of apparent magnesium and calcium absorption in steers fed monesin. J. Anim. Sci., 66(11):2987-2991.

NATIONAL RESEARCH COUNCIL - NRC. 1988. Nutrient requirements of dairy cattle. 6.ed. Washington, D.C. $158 \mathrm{p}$.

RABELLO, T.G., VALADARES FILHO, S.C., COELHO DA SILVA, J.F. et al. Absorções aparentes totais e parciais de cálcio, fósforo, sódio, potássio e magnésio em vacas alimentadas com grão de soja moído. In. REUNÃO ANUAL DA SOCIEDADE BRASILEIRA DE ZOOTECNIA, 31., 1994. Maringá. Anais... Maringá: SBZ, 1994. p.418.

RODRIGUEZ, L.R.R. Consumo alimentar, digestibilidade, balanço de nitrogênio e excreção de minerais, em bovinos (taurinos e zebuínos) e bubalinos. Viçosa, MG: UFV, 1994. 69p. Dissertação (Mestrado em Zootecnia) - Universidade Federal de Viçosa, 1994.

ROSADO, M. Efeito do complexo ácido graxo-cálcio sobre a digestibilidade aparente, alguns parâmetros ruminais e taxa de passagem em vacas lactantes. 1991 Viçosa, MG: UFV, 1991. 96p. Dissertação (Mestrado em Zootecnia) - Universidade Federal de Viçosa, 1991.

SIGNORETTI, R.D., COELHO DA SILVA, J.F., VALADARES FILHO, S.C. et al. 1999. Consumo e absorção aparente total de macroelementos inorgânicos ( $\mathrm{Ca}, \mathrm{P}, \mathrm{Mg}, \mathrm{K}$ e Na), em bezerros da raça Holandesa alimentados com dietas contendo diferentes níveis de volumoso. R. Bras. Zootec., 28(1):178-184.

SILVA, D.J. 1990. Análise de alimentos (Métodos químicos e biológicos). Viçosa, MG: UFV. 166p.

UNIVERSIDADE FEDERAL DE VIÇOSA - UFV. 1995. SAEG - Sistema de análise estatísticas e genética. Viçosa, MG (Apostila).

VALADARES FILHO, S.C., COELHO DA SILVA, J.F., LEÃO, M.I. et al. Absorções aparentes totais e parciais de sódio, potássio e magnésio, cobre e manganês em bovinos alimentados com ração purificada e semipurificada. In: REUNIÃO ANUAL DA SOCIEDADE BRASILEIRA DE ZOOTECNIA, 28, 1991, João Pessoa. Anais... João Pessoa: SBZ, 1991a. p.179.

VALADARES FILHO, S.C., COELHO DA SILVA, J.F., LEÃO, M.I. et al. Absorções aparentes totais e parciais de cálcio e fósforo em bovinos alimentados com ração purificada e semipurificada. In: REUNIÃO ANUAL DA SOCIEDADE BRASILEIRA DE ZOOTECNIA, 28, 1991, João Pessoa. Anais... João Pessoa: SBZ, 1991b. p.178.
Recebido em: 18/10/00 Aceito em: 29/05/01 